INVESTIGACIONES

de HISTORIA ECONÓMICA

2008, otoño, número 12. Pp. 79 a 110

\title{
Las estructuras comerciales de la industria algodonera catalana: el triunfo de los viajantes en el último tercio del siglo XIX
}

\author{
The commercial structures of the Catalan cotton industry: \\ travellers' success in the last third of the $19^{\text {th }}$ century
}

\author{
MARC PRAT SABARTÉS \\ Universidad de Barcelona
}

\begin{abstract}
RESUMEN
La industria algodonera catalana se ha caracterizado por la integración vertical de fabricación y comercialización. Hasta mediados de la década de 1860 esta integración adoptó varias e incompletas formas, pero desde entonces los viajantes se convirtieron en la

pieza fundamental de las estructuras comerciales de los fabricantes algodoneros. Como ya había señalado la historiografía, esto se debió al establecimiento de la red ferroviaria básica. Gracias a esta nueva tecnología de transporte, las empresas grandes y medianas podían cubrir el mercado español con unos pocos vendedores: algunos agentes fijos en las

principales capitales, algunos viajantes alrededor del país. Estos hombres promovían las ventas de la propia empresa y le proporcionaban información sobre los gustos de los consumidores, la actividad de la competencia y la solvencia financiera de los clientes. Se convirtieron, así, en imprescindibles para los fabricantes algodoneros.
\end{abstract}

PALABRAS CLAVE: Industria algodonera, Comercialización, Integración vertical, Redes, España, Siglo XIX Códigos JEL: N6, N7, D3, D8

\section{ABSTRACT}

Catalan cotton industry has been characterised by vertical integration of manufacturing and commercialising. Until the mid 1860s this integration took several and incomplete forms, but since then travellers became the central players in cotton firms' commercial structures. As it has been previously said in the literature, this was because a basic railways network was established at that time. Thanks to this new transport, large and medium size firms could cover all the Spanish market with very few sellers: some permanent agents in main cities and some travellers around the country. These men promoted firms' sales and gave first-hand information about consumers' tastes, competitors and clients' financial soundness. They became then essential for cotton manufacturers.

KEY WORDS: Cotton industry, Commercialisation, Vertical integration, Networks, Spain, $19^{\text {th }}$ Century

JEL Codes: N6, N7, D3, D8 


\section{Introducción ${ }^{1}$}

a historiografía sobre la industrialización catalana ha destacado la fuerte
implicación de los fabricantes de tejidos en la comercialización de sus pro-
ductos. Algunos autores la han presentado como uno de los puntos fuertes del
proceso de industrialización catalán, afirmando que fue precisamente esa vocación
comercial la que permitió a los empresarios catalanes identificar y aprovechar la
oportunidad de desarrollar una industria de bienes de consumo masivo'. Otros, sin
embargo, han visto en ella una consecuencia del atraso de la economía española y

[Fecha de recepción del original, octubre de 2007. Versión definitiva, febrero de 2008]

1 Mi agradecimiento a Jaime Reis, Carles Sudrià, Giovanni Federico y Roberto Romano, que me han ayudado en mi investigación, así como a los participantes en la correspondiente sesión del Congreso de la Association of Business Historians, celebrado en Reading en junio de 2002 (particularmente, a Andrew Godley), y a los participantes en el seminario del Departament d'Història i Institucions Econòmiques de la UB, celebrado en mayo de 2005 (especialmente a Josep M. Benaul, Francesc Valls y Miquel Gutiérrez). También agradezco a Jordi Nadal, Esteve Deu, José Ramón García López y Eloy Fernández Clemente las gestiones realizadas para poder acceder a determinados archivos, y a los tres evaluadores anónimos de la revista, que han contribuido a mejorar el artículo. Los errores corren de mi cuenta.

2 Pierre Vilar vio el despegue industrial como la consecuencia lógica del desarrollo capitalista de la economía catalana del siglo XVIII y observó que, en muchos casos, los mismos protagonistas de la expansión comercial fueron los que participaron en las primeras iniciativas industriales (Vilar, 1965). Francesc Valls ha explicado cómo y por qué el capital comercial catalán de las últimas décadas del Setecientos invirtió en la incipiente industria algodonera (Valls, 2004). Álex Sánchez ha explicado que la crisis del comercio colonial, provocada, primero, por las sucesivas guerras con Inglaterra y Francia, y, después, por la pérdida definitiva de las colonias continentales americanas, llevó a los fabricantes catalanes a reforzar su presencia en el mercado interior español, estableciendo estructuras propias de comercialización (Sánchez, 1989a y 1989b). Josep Fontana y Josep M. Fradera han señalado esta reorientación hacia el mercado español en la década de 1820, que llevó aparejada la apuesta decidida por la industrialización, como la clave que marcó el porvenir económico de la Cataluña del siglo XIX (Fontana, 1971; Fradera, 1987). Si se señalan concomitancias entre fabricación y comercialización en la naciente industria algodonera, también se encuentran en la más tradicional manufactura lanera, especialmente en aquellos segmentos más innovadores. Este fenómeno era consecuencia del proceso de desarrollo de la economía catalana durante el Setecientos y consistió en el establecimiento masivo de negociantes catalanes en los caminos y puertos peninsulares (Torras, 1987 y 1995; Muset, 1993 y 1997; y Pérez Picazo, Segura y Ferrer, 1996). La interrelación entre fabricación y comercialización no fue exclusiva de los prolegómenos de la industrialización. Durante todo el siglo XIX, y aún en el primer tercio del XX, la historiografía señala la implicación comercial de los fabricantes de tejidos catalanes. Josep M. Fradera ha designado la fábrica, el viajante y la tienda como las tres piezas básicas que garantizaron la conquista del mercado interior por parte de los manufacturados catalanes (Fradera, 1987). Josep M. Benaul ha afirmado que la modernización del sector lanero catalán coincidió con una diversificación de sus formas de comercialización y una mayor presencia de los fabricantes en este ámbito del negocio. La proximidad al consumidor fue decisiva para elegir, en cada momento, el nicho de mercado adecuado y fue una de las claves de su éxito en el contexto español (Benaul, 1991, 1992 y 1993). Por otro lado, Esteve Deu ha analizado la comercialización de los tejidos de lana para el período 1870-1935, demostrando que las empresas laneras vendían directamente a muchos clientes y que estaban más implicadas en la comercialización que los fabricantes algodoneros (Deu, 1997, 1999a y 1999b). 
una carga para las empresas textiles ${ }^{3}$. En cualquier caso, todos coinciden en señalar dicha implicación, en claro contraste con el caso británico, donde existía una nítida división de funciones entre fabricantes y comerciantes de tejidos ${ }^{4}$.

Efectivamente, el distrito algodonero del Lancashire se caracterizaba por una marcada especialización vertical empresarial y espacial del proceso productivo hilado, tejido, acabado-, así como por una notoria especialización horizontal de las empresas, puesto que se centraban en pocas variedades de productos, ya fueran hilos, tejidos en crudo o tejidos acabados. La especialización vertical se extendía al ámbito de la comercialización, de modo que los industriales se desentendían completamente de la comercialización. Ésta estaba a cargo de los merchant-converters, que no sólo controlaban los canales de distribución, sino que coordinaban, desde fuera, el proceso productivo. Estas casas comerciales estaban en contacto con los mercados consumidores, por lo que sabían exactamente qué era necesario producir en cada momento y lo encargaban a una de las muchas empresas que lo podían fabricar. El gran tamaño del distrito hacía que el mercado fuera el mejor coordinador de la actividad productiva. Los comerciantes trabajaban a comisión, pagaban a muy corto plazo a los fabricantes y a través de sus sucursales distribuían los tejidos británicos por todo el mundo. Si acordaban con sus clientes que el cobro fuera aplazado, giraban letras de cambio que eran descontadas en las accepting houses, auténticos bancos comerciales que financiaban el circulante entretenido en el proceso de venta ${ }^{5}$.

Este modelo de comercialización ha sido siempre la referencia con la que se ha comparado el sistema español, tanto por los contemporáneos como por parte de los historiadores. Sin embargo, como en tantas otras cosas, los británicos eran más la excepción que la regla. Cuando se analizan los sistemas de comercialización de otras industrias algodoneras se observa que la implicación de los fabricantes era mayor. En Alemania, Francia, Suiza e Italia convivían dos sistemas de comercialización: algunos fabricantes canalizaban sus tejidos a través de casas comerciales, mientras que otros montaban sus propias estructuras de venta. La implicación directa en la función comercial era más habitual en las grandes empresas y cuando había diferenciación de producto. En el primer caso, porque montar una estructura propia

3 Jaume Vicens y Jordi Nadal han destacado la implicación comercial y financiera de los fabricantes catalanes. Mientras sus homólogos británicos se dedicaban sólo a producir, ellos debían actuar, además, como comerciantes y banqueros (Vicens y Llorens, 1958; Nadal y Maluquer, 1985). Estos dos autores se han hecho eco de los testigos de los propios representantes del sector a inicios del siglo XX (Societat d'Estudis Econòmics, 1908; Tallada, 1944).

4 Otras aportaciones sobre las interrelaciones entre fabricación y comercialización textil se encuentran en Solà y Oliva (1997), Oliva (1999) y Galí (2002).

5 Edwards (1967), Chapman (1992), Farnie (1979) y (2004), Whittam (1907), Godley (2001), Pratt (1917), Broadberry y Marrison (2002), Rose (2000) y French (2005). 
tenía economías de escala, y en el segundo, porque la proximidad a la demanda era más necesaria en aquellos segmentos más sujetos a la moda ${ }^{6}$.

Por lo tanto, cuando se amplía el marco comparativo, el sistema de comercialización de la industria algodonera catalana no necesita explicarse por el atraso relativo de la economía española. En el caso catalán, como en otras industrias algodoneras europeas, el menor tamaño del distrito industrial llevaba a una mayor integración vertical de las distintas fases productivas, a un mayor papel de los fabricantes en la coordinación del proceso productivo y, en consecuencia, a una mayor implicación de éstos en la comercialización ${ }^{7}$.

La figura que mejor ha simbolizado el esfuerzo comercial de los fabricantes catalanes es el viajante, probablemente el personaje que más ha influido en la construcción de la identidad catalana en el resto de España. Quienes se recorrían el país con una maleta llena de muestras de tejidos encarnaban el espíritu comercial, el carácter negociador, la laboriosidad y la tacañería que se atribuyen generalmente a los habitantes del Principado.

Este artículo tiene por objeto estudiar cuándo y por qué los viajantes se convirtieron en la pieza angular de la comercialización de tejidos en España. Aunque habrá referencias a las otras fibras, el análisis se centrará en la industria algodonera. La principal fuente utilizada son varios archivos empresariales, concretamente seis de fábricas algodoneras, dos de empresas que fabricaban y a la vez tenían almacén en Madrid y Valencia, respectivamente, y dos de mayoristas de tejidos situados en Zaragoza y Oviedo ${ }^{8}$. A partir de esta documentación, se pretende contrastar la afirmación de Jaume Vicens según la cual la irrupción de los viajantes coincidió con la implantación del ferrocarril. Para ello, en los dos primeros apartados se rastreará su presencia antes y después, respectivamente, de mediados de la década de 1860, justo cuando la red básica ferroviaria entró en funcionamiento. A continuación, en el siguiente apartado se analizará, a partir de la correspondencia comercial, las funciones que desempeñaban los viajantes y los agentes fijos, descubriendo por qué se convirtieron en pieza fundamental de la comercialización de las fábricas algodoneras catalanas. Por último, veremos hasta qué punto este sistema se mantuvo en el primer tercio del siglo $\mathrm{XX}$.

6 Para Francia, Chassagne (1991), Fohlen (1956) y Forrester (1921). Para Alemania, Dehn (1913), Clark (1908b) y Brown (1992) y (1995). Para Suiza, Besso (1910). Para Italia, Castronovo (1965); Romano (1980), (1992a) y (1992b); Odell (1912); Besso (1910); Bova (1993); Clark (1908a); y Einaudi (1900).

Rosés (1997) y (1998), capítulo 8; y Prat (2007).

Los principales documentos consultados han sido los libros mayores, diarios e inventarios de las empresas correspondientes, así como su correspondencia comercial, tanto cartas enviadas como recibidas. Cuando éstas eran escasas, se han consultado todas. Cuando eran abundantes, para determinados años se han realizado unas muestras de clientes y un seguimiento exhaustivo de los viajantes y agentes fijos. 


\section{Sin viajantes en el segundo tercio del siglo XIX}

En el período 1840-1865, las referencias a los viajantes son muy escasas. De las fuentes consultadas, la más antigua la encontramos en la correspondencia de Muntadas Hnos., cuando en diciembre de 1841 y abril de 1842 dos personas del almacén de Madrid realizan dos viajes, a Aranjuez y Toledo, respectivamente, en busca de clientes. Llevan con ellos los muestrarios de los productos que pretenden vender 9 . Aunque se trata del mismo mecanismo que más tarde se generalizará para todo el mercado español, en este caso los viajes se realizan a dos poblaciones muy cercanas a Madrid, donde los Muntadas acaban de establecer un almacén.

También en 1859 los Batllori, el otro fabricante-comerciante analizado, recurren ocasionalmente a un viajante, Juan Claviera, para obtener pedidos, precisamente también en Aranjuez y Toledo ${ }^{10}$. Aunque se trate de las mismas poblaciones, en este caso las bases comerciales de la empresa se encuentran mucho más alejadas, en Barcelona y Valencia. Sin embargo, todo parece indicar que la figura del viajante juega un papel marginal en el sistema de ventas de la empresa.

En general, la impresión que sacamos del análisis de los archivos de empresas algodoneras y de los mayoristas de provincias es que, para el período 1840-1865, la industria algodonera no dispone de viajantes. En la correspondencia del mayorista zaragozano de tejidos $V d a$. de Fortea de los años 1842-1845 no aparece ningún viajante proveniente de una algodonera que visite dicha casa ${ }^{11}$. Sólo Ramón Galí, fabricante lanero de Terrassa, les visitó para comprar lana en bruto. De hecho, la historiografía ya ha señalado la mayor precocidad comercial de los fabricantes laneros. Así, Fradera explica que en la década de 1820 las fábricas laneras de la familia Oller de Terrassa ya disponían de un viajante que cubría la mitad norte peninsular y que dicha estructura se reforzó en los años treinta con otro que cubría la mitad sur y la instalación de varios almacenes ${ }^{12}$. El interés de los fabricantes laneros en el mercado interior era doble, puesto que también dependían del mismo para su abastecimiento de lana, y ello contribuye a explicar la temprana presencia de sus estructuras comerciales $^{13}$.

Arxiu del Museu Tèxtil i l'Estampació de Premià de Mar (AMTEPM, en adelante), copiador del almacén de Madrid, n. 615, Carta a Muntadas Hnos. de Barcelona, 20/04/1842, n. 70. Respecto al viaje a Aranjuez: "La nota que VV. nos piden relativa á la venta de los géneros de este Deposito esperamos que Jose regrese de Aranjuez para remitirla", AMTEPM, copiador del almacén de Madrid, n. 615, Carta a Muntadas Hnos. de Barcelona, 26/11/1841, n. 30. Arxiu Històric Municipal de Barcelona (AHMB, en adelante), Fons comercial, Carta a Joaquín Almansa del 13/08/1859, copiador de cartas B.594, p. 68.

11 Para un estudio de los primeros años de Fortea, véase Gómez Zorraquino (1990).

12 Fradera (1987), pp. 288-293.

13 Benaul (1991) y (1993); y Gómez Zorraquino (1990). 
Por otro lado, de las cinco fábricas algodoneras analizadas ${ }^{14}$, ninguna de ellas empleaba viajantes durante este período. Por ejemplo, en las cartas comerciales de $L a$ Rambla de 1854-1855 o en las de La España Industrial de 1860 y 1865, no se menciona ningún viajante, y en aquellas empresas algodoneras en las que no se ha conservado la correspondencia, los libros mayores no contienen ninguna evidencia de la existencia de viajantes: ni Miquel Puig y Cía. en 1850 y en 1858, ni Burés en 1861, ni Viladomiu en 1866-1868. Tampoco los Masaveu, comerciantes de tejidos en Oviedo, recibieron en 1865 ningún viajante de fabricantes algodoneros catalanes, aunque sí de dos laneros, uno de Terrassa y otro de Alcoi, y de un fabricante de pañuelos sevillano ${ }^{15}$.

Además de no tener viajantes, de los cinco fabricantes mencionados, cuatro no tuvieron durante las décadas de los cincuenta y sesenta ningún representante comercial fuera de Barcelona, mientras que La España Industrial realizó en Zaragoza un intento en el período 1855-1859, que acabó en fracaso.

Aparte de las fuentes empresariales, los expedientes del Tribunal de Comercio de Barcelona también confirman la escasa presencia de viajantes durante el período 1840-1865. Sin embargo, hay algunas excepciones, sobre todo para los años sesenta. Así, nos consta que, en 1861, el fabricante de muselinas Luis Balius, de Sant Genís de Vilassar, envía un viajante al comerciante de Alicante José Vich:

[de José Vich a Luis Balius] “... hoy se me ha presentado un viajante de su casa con muestras de sus entrefinas 6/4 marca Abeja de cuya muestra me he quedado una tira y adjunto le mando la mitad de ésta..."16.

Balius es un fabricante pequeño, cuenta con 30 telares y 36 trabajadores, por lo que no deja de ser significativo que ya utilice un viajante a principios de los años sesenta.

El testimonio más rico de que disponemos sobre la existencia de viajantes en el comercio textil de este período es un expediente del Tribunal de Comercio de 1863. En él se discute el conflicto entre Francisco Zanné y Oliver, gerente de la casa comercial barcelonesa Zanné y Coromines, y Gerónimo Pujol, que ha sido viajante suyo ${ }^{17}$.

14 Estas cinco empresas son: La España Industrial, La Rambla, Viladomiu, Miquel Puig y Cía. y Burés. De Manufacturas Valls no se conserva documentación para ese período.

15 El fabricante lanero de Terrassa era Antonio Galí y Cía.: “...no puedo proponer al Sr. Fernández lo que Vds. desean y sí creo más justo que lo arregle su viajante una vez que poco tardará en pasar por esta...". Archivo Masaveu (AM, en adelante), Carta enviada por Masaveu a Antonio Galí y Cía. de Terrassa, 3/5/1865, Copiador n. 7, p. 197. El de Alcoi era Antonio Colomina e hijos, y el fabricante de pañuelos de Sevilla, Manuel del Castillo. Para un estudio en profundidad de los Masaveu, véase García López (1987).

16 Carta firmada en Alicante el 22/06/1861. Archivo Histórico de la Corona de Aragón (AHCA, en adelante), Expediente de “D. Luís Balius vs D. José Vich" p. 1 (exp. 10.097 del T. C., año 1862).

17 AHCA, Expediente de "Francisco Zanné y Oliver vs Gerónimo Pujol. Exhorto del Tribunal de Comercio de Valladolid. Recepción de testimonios" (exp. 10.117 del T.C., año 1863). 
A partir de dicho expediente queda claro no sólo que Zanné y Coromines tiene un viajante a principios de la década de los sesenta ${ }^{18}$, sino que también los tienen Francisco Larroude y Agustín Martín, ambos comerciantes establecidos en Barcelona ${ }^{19}$. Asimismo, por la familiaridad con que hablan del tema los cuatro testigos del proceso, da la impresión de que la figura del viajante empieza en esta época a ser algo habitual en el comercio textil español. El expediente incluye una discusión en la que se contraponen la figura del comisionista con establecimiento propio, que actúa independientemente y asume riesgos empresariales, y la del viajante "dependiente" de la casa de comercio, que sólo recibe órdenes y no actúa nunca en nombre propio, hecho que apunta a que los inicios de los sesenta eran una época de cambio. Mientras que las casas de comisión eran uno de los pilares del comercio textil de las décadas de los cuarenta y cincuenta, el viajante era una figura nueva que anunciaba un nuevo modelo de comercialización. En cualquier caso, los testigos explican el comportamiento habitual de los viajantes:

“... según el uso recibido en Barcelona, las casas respetables de su comercio, dedicadas al comercio de comisión, se conviene con los viajantes que eligen sin que se consignen por escrito las condiciones de ejecución del contrato de viajes en comisión"20.

“... generalmente se contrata verbalmente que se presentarán las muestras en los puntos que se le designen mediante tanto ó cuanto de comisión"21.

“... dichos viajantes en comisión toman de los corresponsales de las casas por cuya cuenta se ocupan, las cantidades que creen necesarias para los gastos de los viajes y (...) al regresar de estos presentan á sus comitentes cuenta documentada de dichos gastos respondiendo siempre de la cantidad invertida y no justificada, como es uso generalmente recibido en la mencionada plaza de Barcelona"22.

Es decir, los viajantes son unos empleados de las casas comerciales que se dedican a visitar clientes por la geografía española con un muestrario, con la intención de obtener pedidos para dichas casas, y que son remunerados con las comisiones de las ventas que consiguen. Parece que a inicios de los sesenta son las casas comerciales,

Sabemos que "Pujol escribió a dicha casa Zanne y Oliver desde Zaragoza en veinticinco de diciembre del expresado año mil ochocientos sesenta, dando cuenta de las gestiones propias de su comision que ya habia practicado en la indicada ciudad". Preguntas n. 3 y 4 de Francisco Zanné, expediente citado en la nota 16. “Gerónimo Pujol estuvo de dependiente en la casa de comercio de D. Francisco Larroude y compañía de Barcelona por cierto periodo". Pregunta n. 2 de Francisco Zanné, expediente citado en la nota 16.

20 Pregunta n. 5 de Francisco Zanné, expediente citado en la nota 16.

21 Respuesta de Francisco Larroude a la pregunta n. 4 de Gerónimo Pujol, expediente citado en la nota 16.

22 Pregunta n. 7 de Francisco Zanné, expediente citado en la nota 16. 
y no los fabricantes, los que disponen de esta figura, aunque muchas empresas comerciales contaban entre sus socios con industriales. De hecho, la escasa presencia de viajantes en el período 1840-1865 no significa que los fabricantes no estuvieran implicados en la comercialización. Como demuestra la documentación notarial y las fuentes empresariales, la integración entre fabricación y comercialización en el sector algodonero catalán era un fenómeno habitual, aunque se producía, en distintos modos, de forma parcial ${ }^{23}$. La razón de ello era que, por una parte, existían fuertes incentivos para realizar ambas actividades dentro de una misma empresa, pero, por otra, era bastante difícil para una fábrica tener una estructura comercial propia que abarcara todo el mercado español.

Entre los incentivos que había para integrar producción y comercialización estaban el deseo de los fabricantes de fomentar la venta de sus propios productos, la voluntad de ahorrarse las comisiones de los intermediarios y, sobre todo, la necesidad de feed-back entre oferta y demanda. Sin embargo, con la tecnología del transporte anterior al ferrocarril, estar cerca de la demanda significaba tener un almacén abierto en las principales ciudades. Ningún fabricante podía con este sistema cubrir una gran parte del mercado nacional y, por consiguiente, debía especializarse en uno o varios mercados regionales. Además, debido a que cada fabricante sólo podía producir un abanico limitado de tejidos y que no tenía sentido mantener un almacén sólo para ellos, los fabricantes que montaban su propia estructura comercial se veían envueltos en el comercio de géneros producidos por otros.

Así pues, habitualmente se registraba una integración parcial de fabricación y comercialización; es decir, que nunca una estructura comercial se dedicaba a distribuir productos de una única empresa. A veces esta integración parcial consistía en unos fabricantes que, estableciendo una sucursal para sus propios productos, acababan haciendo de intermediarios de los géneros de otros fabricantes. Otras veces el arreglo consistía en una participación de un fabricante en el capital de una sociedad comercial, a través de la cual canalizaba sus géneros, o viceversa, en la participación de un comerciante en una empresa fabril a cambio de controlar la esfera comercial de la misma. Paralelamente, una parte importante de la producción se comercializaba a través de comerciantes independientes: grandes casas de comisión con sede en Barcelona y en otras ciudades españolas, o mayoristas de provincias que visitaban la ciudad condal - y las ciudades laneras de Sabadell y Terrassa - para proveerse de géneros catalanes $^{24}$. La España Industrial vendía en 1860 el 71 por 100 de su producción en Barcelona, mientras que La Rambla lo hacía en un 61 por 100 y Sedó, en 1869, en un 87 por 100.

\footnotetext{
23 Analizo en profundidad la incidencia de la integración entre fabricación y comercialización en el período 1840-1865, así como las formas que adoptó, en Prat (2004), (2005) y (2006). 
En resumen, en el comercio textil catalán de mediados del XIX, la mano invisible de Adam Smith no era la única que coordinaba las necesidades de los consumidores con las posibilidades del sistema productivo. Una parte significativa de esa coordinación se producía dentro de las empresas. Había incentivos para que así fuera, pero también había obstáculos para que se llevase a cabo. Obstáculos que la implantación del ferrocarril eliminaría en el último tercio de siglo.

\section{Aparición de los viajantes en el último tercio del siglo XIX}

Las cosas cambiaron radicalmente en el último tercio del siglo XIX. La documentación de las fábricas algodoneras estudiadas demuestra que en la década de los setenta algunas fábricas empezaron a valerse de viajantes y agentes fijos de forma sistemática para comercializar sus tejidos y que, durante los años ochenta y noventa, el sistema se generalizó para el conjunto del sector. A finales de siglo, la mayoría de las fábricas catalanas tenían sus propios representantes trabajando por todo el mercado español.

En 1865 La España Industrial aún no tenía ninguna estructura comercial fuera de Barcelona. Sin embargo, en 1870 ya tenía a tres personas trabajando en su nueva estructura de ventas. Uno de ellos, José Sureda, era un viajante que cubría él solo el valle del Ebro, el País Vasco, Cantabria, ambas Castillas y Levante ${ }^{25}$. Por ejemplo, entre el 2 de abril y el 18 de julio visitó todas las poblaciones que aparecen en el Mapa 1. Otro, Andrés G. Gallardo, trabajaba en Andalucía, Extremadura y Albacete. El tercero, Díaz y Clavo, obtenía algunas comisiones vendiendo en Cádiz y provincia (Mapa 2).

Observando con detalle la actividad de estos vendedores, se demuestra que justo en este momento se estaba creando la estructura comercial de la empresa. Por ejemplo, a José Sureda La España Industrial le decía dónde tenía que ir y con qué clientes tenía que hablar:

“Después haya visitado V. esos parroquianos emprenderá V. la ruta que le designamos al pie de la presente, visitando las casas que le indicamos, sin perjuicio de que si tiene V. noticia de alguna otra que sea bien reputada que también podrá V. visitarla (...) Itinerario que deberá seguir en su escursion á las Provincias de Alicante y Murcia y los nombres de las casas que deberá visitar"26. 


\section{MAPA 1}

RECORRIDO DE JOSÉ SUREDA ENTRE EL 2 DE ABRIL Y EL 18 DE JULIO DE 1870

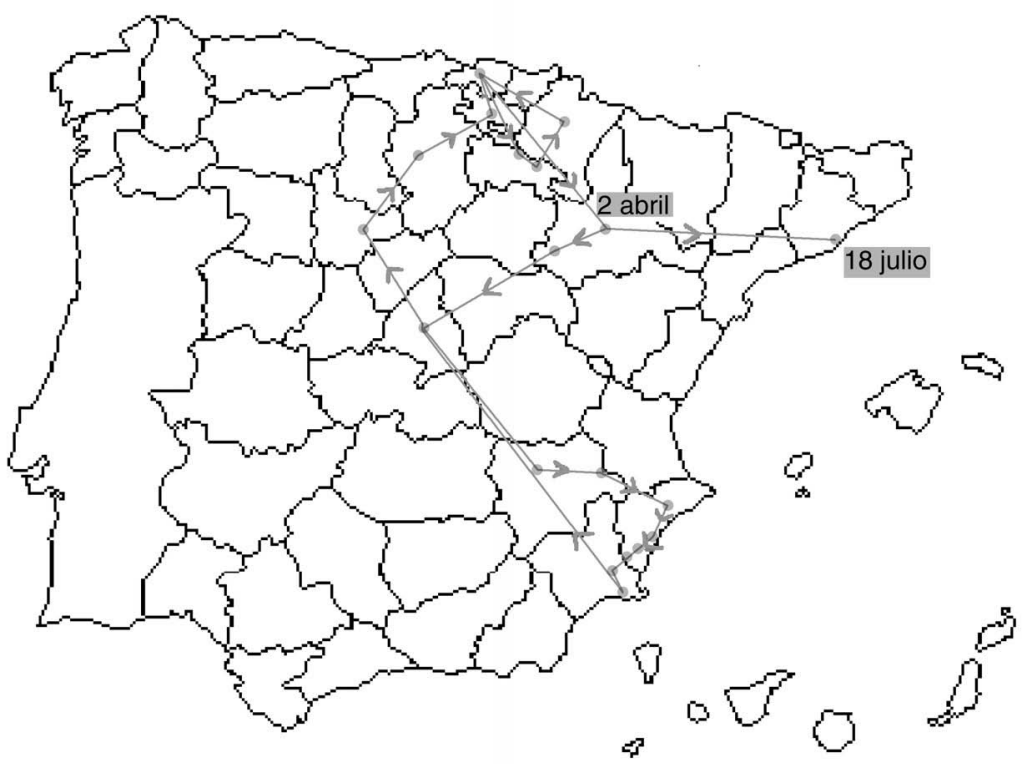

Fuentes: Arxiu Nacional de Catalunya (ANC, en adelante), Libros mayores y cartas de La España Industrial en 1870.

Esto demuestra que él era nuevo en la zona y que la empresa estaba diseñando las rutas que habría que seguir a partir de la lista de mayoristas que tenían. Con Andrés G. y Gallardo pasaba algo similar. En diciembre de 1869 la empresa le sugirió que hiciera un viaje a Extremadura:

“...tal vez convendría que hiciese una escursion en la Prova. de Estremadura de donde nos han pedido algunos muestrarios de esta clase"27,

pero el viajante prefirió permanecer en Andalucía, por temor a que los potenciales clientes hicieran encargos a la competencia durante su ausencia ${ }^{28}$. La empresa estuvo de acuerdo y le aconsejó que evitara la plaza de Málaga, porque todos sus

27 ANC, Carta de La España Industrial a Andrés G. y Gallardo, 28/12/1869, copiador 26.2.30, p. 33.

28 ANC, Carta de Andrés G. y Gallardo desde Cádiz a La España Industrial, 9/2/1870, caja 27.58, n. 135. 


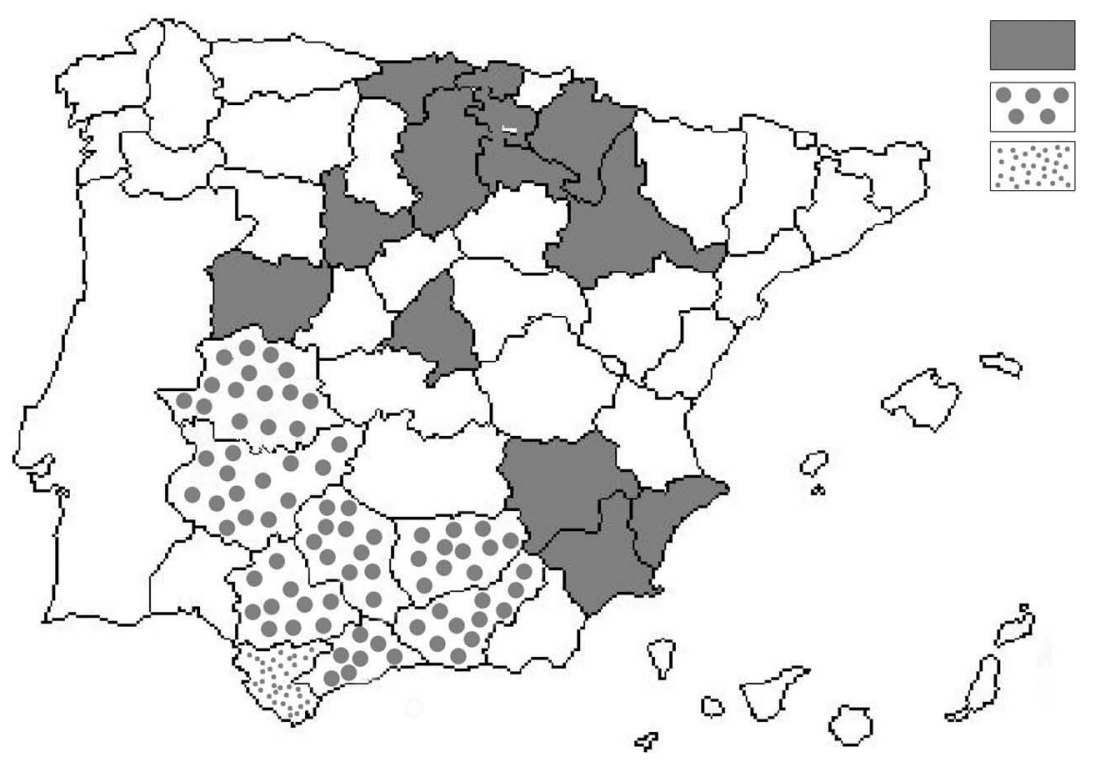

José Sureda

Andrés Gallardo

Díaz y Clavo

Fuentes: Véase Mapa 1.

mayoristas estaban haciendo compras en Barcelona ${ }^{29}$. Al final, en febrero, Andrés G. y Gallardo realizó un viaje a Extremadura.

Así pues, tanto la empresa como los viajantes eran nuevos en este sistema. Estaban construyendo la red y las decisiones se tomaban sobre la marcha. Otra prueba de que el sistema era nuevo es que muchos de los clientes visitados por José Sureda acostumbraban a encargar los productos de La España Industrial a través de sus corresponsales en Barcelona y que, aunque ahora podían hacer los encargos directamente a través del viajante, preferían seguir usando el viejo sistema ${ }^{30}$.

En definitiva, podemos concluir que La España Industrial empezó a establecer su sistema de viajantes entre 1865 y 1870. Para 1880 su estructura comercial se había

29 ANC, Carta de La España Industrial a Andrés G. y Gallardo, 11/2/1870, copiador 26.2.30, p. 92.

30 ANC, Carta de José Sureda, desde Madrid, a La España Industrial, 25/01/1870, caja 27.60, n. 179; y ANC,

Carta de José Sureda, desde Valladolid, a La España Industrial, 13/2/1870, caja 27.60, n. 190. 


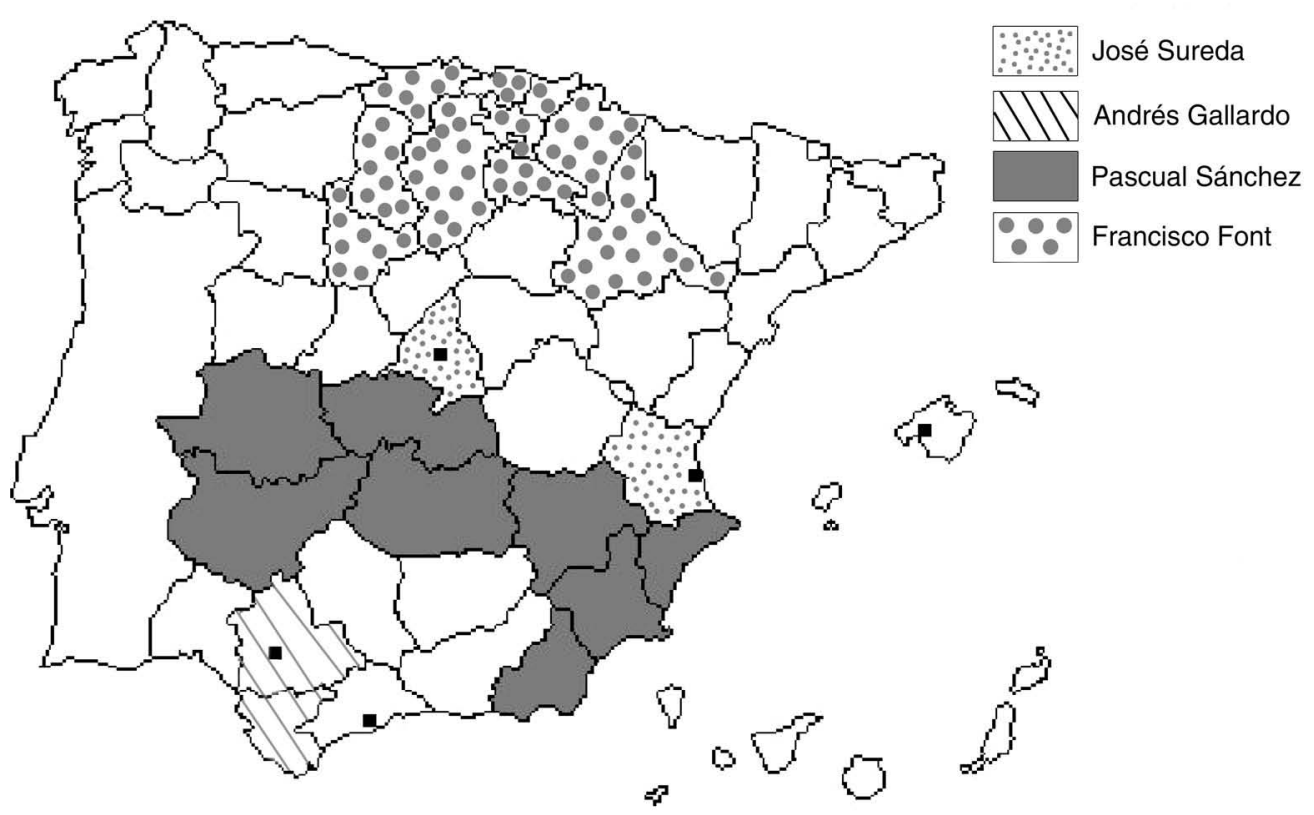

Fuentes: ANC, Libros mayores y cartas de La España Industrial en 1880.

ampliado notablemente. Contaba con tres agentes permanentes - en Madrid, Palma de Mallorca y Málaga—, dos viajantes —-Francisco Font, que cubría el Valle del Ebro, la costa cantábrica y el norte de Castilla; y José Sureda, que viajaba a Madrid y Valencia- y dos agentes permanentes que también viajaban —establecidos en Valencia y Sevilla- (ver Mapa 3). De hecho, dos de las tres personas que trabajaban en la red comercial de la empresa en 1870 seguían perteneciendo a la misma en 1880: Andrés G. y Gallardo, que continuaba cubriendo el mercado andaluz desde Sevilla, y José Sureda, que probablemente desempeñaba un papel de coordinador de los otros agentes y viajantes. En definitiva, La España Industrial disponía ya en 1880 de una red comercial propia que cubría casi todo el territorio español, con la excepción de Galicia y Canarias.

En 1900 la algodonera de Sants tenía tres agentes permanentes en Madrid, Sevilla y Valencia, y dos viajantes -Francisco Font, que sólo realizó un viaje a Bilbao y Santander, y José Vidal Calsina, que cubría el valle del Ebro, la costa cantábrica, Galicia, el norte de Castilla y Levante (Mapa 4)—. De estas cinco personas, dos ya traba- 


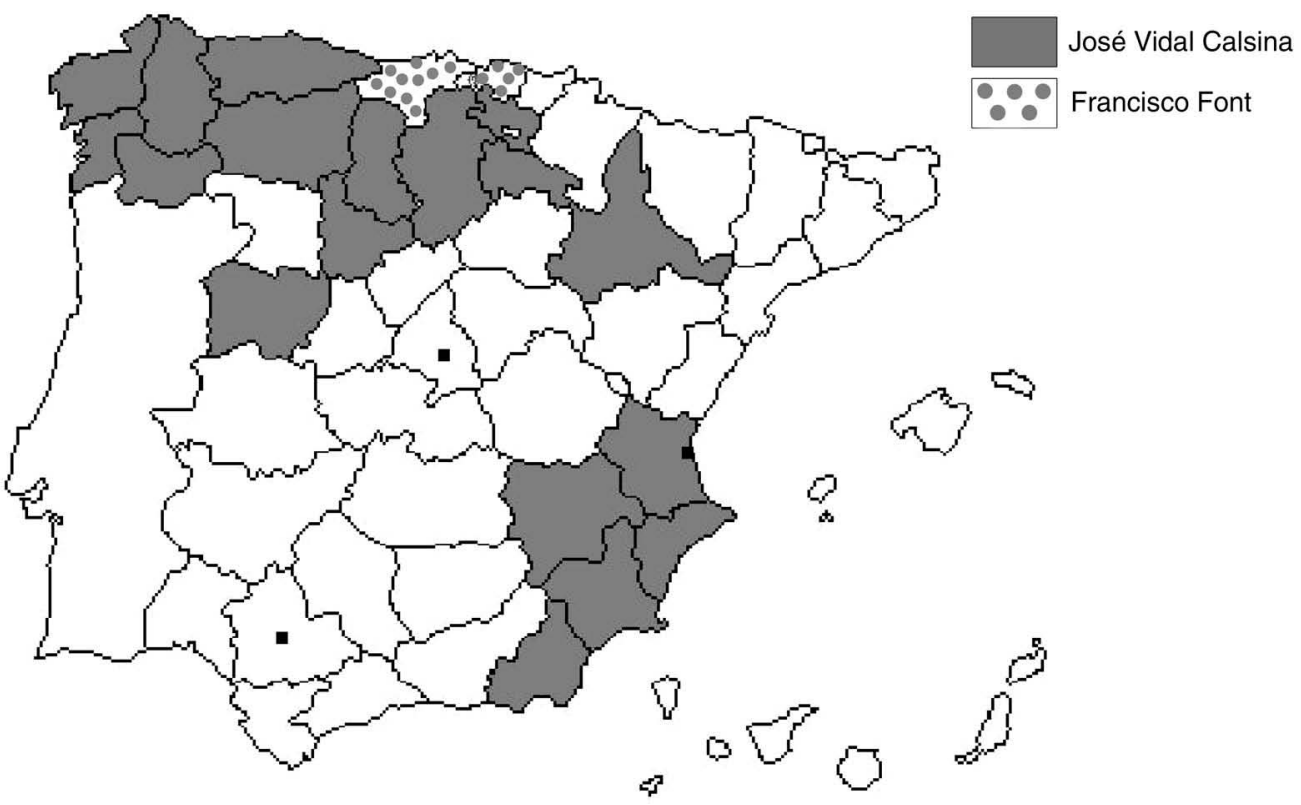

Fuentes: ANC, Libros mayores y cartas de La España Industrial en 1900.

jaban para la empresa en 1880: Francisco Font, como viajante, y Pascual Sánchez, establecido en Valencia. Así pues, en 1900 La España Industrial mantenía contacto directo con todo el mercado peninsular español.

La cronología de la formación de la red comercial de esta empresa coincide con la extensión de la red ferroviaria. A pesar de que ya en 1848 se creó la primera línea de ferrocarril en España, entre Barcelona y Mataró, a mediados de los cincuenta el tren prácticamente no llegaba a ningún sitio. Durante el Bienio Progresista se promulgó la Ley general de ferrocarriles (1855) y la Ley general de bancos y sociedades de crédito (1856) que darían un fuerte impulso a su construcción. Entre 1856 y 1866 se creó prácticamente toda la red básica, revolucionando el transporte en España. A partir de esta última fecha, un viajante podía recorrer, en mucho menos tiempo que cuando sólo había diligencias, grandes áreas del territorio español. Recordemos que en 1865 La España Industrial aún no tenía ningún vendedor y que, en cambio, en 1870 ya contaba con tres personas trabajando fuera de Barcelona. 
Como ya había señalado Jaume Vicens ${ }^{31}$, el establecimiento de la red ferroviaria, con la mejora consiguiente de las comunicaciones, llevó al triunfo de un nuevo modelo de comercialización, basado en la figura del viajante. Con la nueva tecnología de transporte, una empresa textil media podía tener presencia directa en todo el mercado español con cuatro o cinco personas. Así pues, lo que a mediados de siglo no estaba al alcance ni de la anónima algodonera con más capital, a finales del mismo se lo podía permitir la mayoría de las empresas del sector: integrar completamente la comercialización.

Antes de 1866 el viaje que José Sureda realizó entre el 10 de enero y el 31 de marzo de 1870, en el que pasó por Aragón, Madrid, Castilla la Vieja, País Vasco, Cantabria, La Rioja, Navarra y otra vez Aragón, hubiera durado mucho más ${ }^{32}$. Y lo mismo el que realizó entre el 2 de abril y el 18 de julio, que comprendió, además de las regiones ya citadas, Castilla-La Mancha, Murcia y toda la región valenciana $^{33}$. Está claro que el ferrocarril permitía que una sola persona se recorriera medio país dos o tres veces al año y que con muy pocas personas se pudiera cubrir directamente todo el mercado español. Incluso la falta de presencia directa en Galicia, tanto en 1870 como en 1880, coincidía con la ausencia de ferrocarril en esa zona. En 1900 ya llegaban allí tanto el ferrocarril como los viajantes de La España Industrial.

En todo caso, la extensión de la red ferroviaria era la condición necesaria para la adopción del sistema de viajantes, pero no la suficiente. Todo parece indicar que la empresa dirigida por los Muntadas fue de las primeras algodoneras en tener una red comercial propia que cubriera prácticamente todo el territorio español. Las otras cuyos archivos hemos podido analizar incorporaron los viajantes más tarde. Por ejemplo, mientras La España Industrial empezó a construir su propia estructura comercial fuera de Barcelona entre 1865 y 1870, La Rambla aún no tenía en 1880 ningún viajante ni agente comercial, momento en el cual la empresa de Sants cubría ya prácticamente toda la península. Sólo en 1895 empezó La Rambla a establecer su propia red comercial: dos agentes - uno en Madrid y otro en Zaragoza- y un viajante en la zona de Navarra y el País Vasco. Así, aún en ese año, su red sólo cubría un tercio del país (Mapa 5).

\footnotetext{
31 Vicens y Llorens (1958).

32 Entre estas dos fechas pasó por las siguientes poblaciones: Zaragoza, Calatayud, Madrid, Salamanca, Valladolid, Burgos, Vitoria, Bilbao, Santander, Bilbao, Haro, Logroño, Tudela, Pamplona, Zaragoza, Tudela y Tafalla.

33 El recorrido en esta ocasión fue: Zaragoza, Calatayud, Madrid, Albacete, Almansa, Alcoi, Alicante, Elche, Orihuela, Murcia, Cartagena, Madrid, Valladolid, Burgos, Vitoria, Bilbao, Haro, Logroño, Pamplona, Bilbao, Zaragoza y Barcelona.
} 


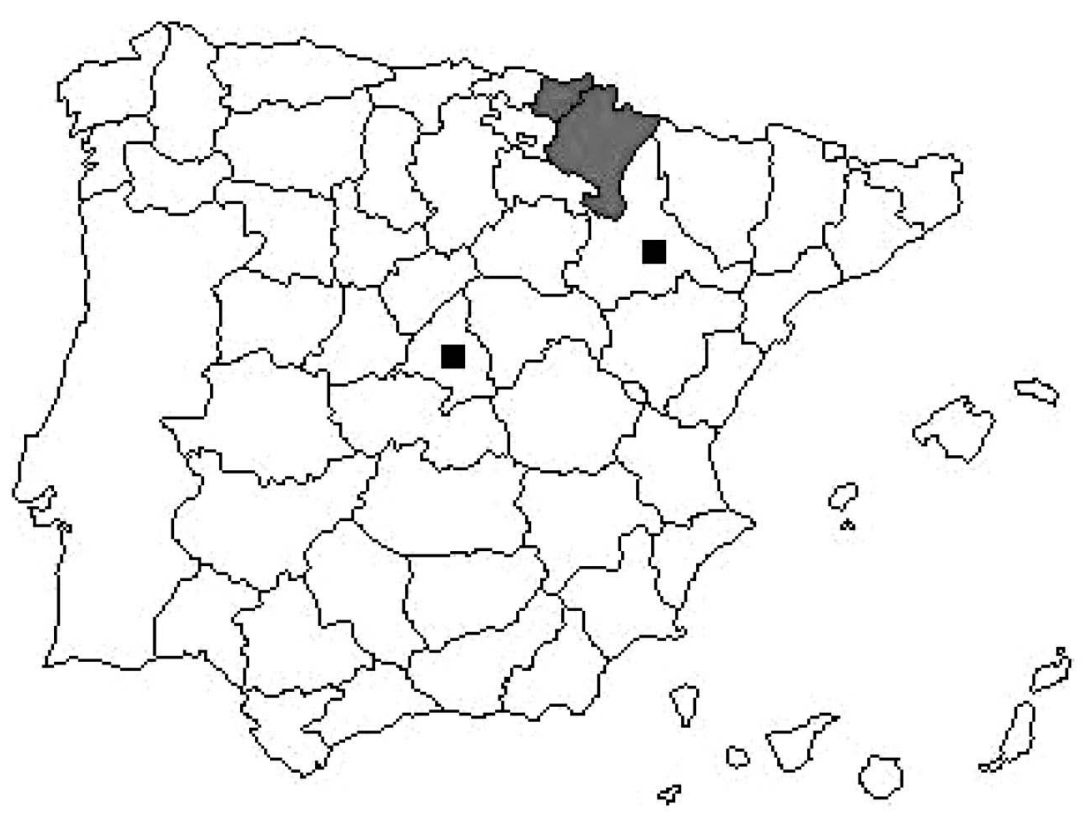

Fuente: Arxiu Històric Comarcal de Vilanova i la Geltrú (AHCVG, en adelante), Libros mayores y cartas de La Rambla en 1895.

Si analizamos los libros mayores de las empresas que carecen de correspondencia comercial, encontramos un patrón más parecido al de La Rambla que al de La España Industrial. Por ejemplo, Viladomiu no tenía ningún agente fijo ni viajante en los años 1866-1868, ni en 1873, ni en 1886. Sin embargo, en 1893 disponía de dos agentes fijos, uno en Madrid y otro en Murcia; tres en 1894 (otro en Sevilla); y cuatro en 1895 (el nuevo, en La Coruña) ${ }^{34}$. En 1901 tenía dos agentes fijos (en Murcia y en Málaga), a los que en 1902-1904 se les había añadido un viajante ${ }^{35}$. En 1905 tenía cuatro agentes fijos y cuatro viajantes ${ }^{36}$. Por su parte, Miquel Puig y Cía. no tenía ni agentes ni La Coruña.

35 Juan Abizanda en Murcia, Francisco Lozano en Málaga y Antonio Seguer como viajante.

36 Los dos nuevos agentes fijos eran Francisco Sancho en Valencia y Antonio Domenech en Granada, mientras que los tres nuevos viajantes eran Rafael Tintoré, Jacinto Serra y Antonio Sala. 
CUADRO 1

NÚMERO DE VIAJANTES Y AGENTES FIJOS

\begin{tabular}{lccccc}
\hline & 1870 & 1880 & 1895 & 1900 & 1905 \\
\hline $\begin{array}{l}\text { La España Industrial } \\
\begin{array}{l}\text { La Rambla } \\
\text { Viladomiu }\end{array}\end{array}$ & 3 & 7 & & 5 & \\
Sedó & & & 3 & & 8 \\
\hline $\begin{array}{l}\text { Fuentes: ANC, Libros mayores y cartas de La España Industrial, Viladomiu y Sedó } \\
\text { para varios años; y AHCVG, Libros mayores y cartas de La Rambla para } \\
\text { varios años. }\end{array}$ &
\end{tabular}

viajantes en 1850 ni en 1857, ni sus sucesoras en 1871, ni en 1881. Sin embargo, en 1900, su sucesor Antonio Sedó y Cía. tenía un agente fijo en Madrid ${ }^{37}$ (Cuadro 1).

En resumen, La Rambla empezó a tener estructura comercial propia entre 1880 y 1895, Viladomiu entre 1886 y 1893 y A. Sedó y Cía. entre 1881 y 1900 (Cuadro 1). Queda pues claro que en el último tercio de siglo se produjo un cambio fundamental en la forma de comercializar los tejidos de algodón catalanes. La posibilidad de tener viajantes, junto con el recurso a agentes fijos, permitió a las empresas integrar su comercialización. Con ritmos distintos, la mayoría de las empresas adoptaron el nuevo sistema entre 1870 y 1900.

¿Por qué estos ritmos distintos en la adopción del nuevo sistema? Se pueden vislumbrar dos factores que podían influir en el ritmo de creación de la estructura comercial propia: el tamaño de la empresa y el grado de diferenciación de producto. Es evidente que una empresa grande lo tenía más fácil para integrar la comercialización, ya que ésta siempre tiene un componente de economías de escala. Así, aunque la muestra de empresas con la que hemos trabajado es tan pequeña que no tiene ninguna representatividad estadística, no es ninguna casualidad que la primera en adoptar el sistema de viajantes fuera la mayor anónima textil del país.

Respecto a la diferenciación de producto, es lógico pensar que aquellas empresas cuyos tejidos fueran diferenciados, contaran con un componente importante de diseño y dependieran de las fluctuaciones de la moda, tuvieran más necesidad de disponer de gente propia cerca de los consumidores. También en este caso La España

37 Su nombre era A. J. Vázquez y viajó a Valencia el 12/02/1900. 
Industrial tenía más motivos para integrar la comercialización, pues su principal baza eran los diseños de sus estampados, que cambiaban cada año y con los que intentaba distinguirse de los demás competidores, mientras que La Rambla, Sedó y Viladomiu producían tejidos crudos o blancos, muy estandarizados y que no cambiaban de un año a otro ${ }^{38}$. Precisamente la ampliación del abanico de productos que realizó La Rambla en las últimas décadas del siglo XIX puede relacionarse con su cambio de estrategia comercializadora. Cuando analicemos las actividades de los vendedores, veremos que informar a la empresa de los gustos de los consumidores y de los diseños que tenían más éxito era una parte importante de su trabajo.

Por otro lado, la mayor implicación de los fabricantes laneros catalanes, en comparación con los algodoneros, puede también relacionarse, como señala Benaul, con la apuesta de los primeros por los tejidos de novedades, muy ligados a las fluctuaciones de la moda. Esta mayor o más pronta vocación comercial ya ha sido señalada por la historiografía ${ }^{39}$, y puede comprobarse al analizar los proveedores de Masaveu. Efectivamente, en la correspondencia del comerciante asturiano se observa ya la presencia de viajantes de empresas laneras en 1865 y más aún en 1878, mientras que en esos años no aparece aún ningún representante de las algodoneras catalanas. Sí que aparecen, en cambio, en 1894-1896 $6^{40}$.

Una cuestión que se plantea al observar los cambios del último tercio del siglo XIX es por qué los agentes fijos no aparecieron antes del desarrollo del ferrocarril, pues su labor no dependía de la rapidez y regularidad en las comunicaciones. Las empresas que tenían mayores incentivos para integrar su comercialización hubieran podido montar una red de agentes fijos en las principales ciudades sin necesidad de esperar la revolución en las infraestructuras viarias. Sin embargo, si observamos detenidamente las estructuras comerciales que se montaron en el último tercio del siglo XIX, el empleo de viajantes siempre iba acompañado de la presencia de agen-

Raimon Soler muestra con distintos inventarios que, entre 1850 y 1865, las cinco principales variedades producidas por La Rambla eran empesas, curados, guineas, semi-guineas y semi-retores. La primera de ellas era tejido en crudo, mientras que las otras eran blancas (Soler, 2000, pp. 153-155). Para los industriales laneros, véanse Benaul (1991) y (1992); y Deu (1997), (1999a) y (1999b). Ver también Fradera (1987), pp. 288-293.

40 Como ya hemos dicho antes, en una muestra de cartas del año 1865 aparecen tres viajantes, uno de un lanero catalán, otro de un lanero de Alcoi y un tercero de un fabricante sevillano de pañuelos. En 1878 hemos encontrado cinco proveedores que se valían de viajantes, siendo tres de ellos laneros catalanes — Sert Hnos. y Solá, Hijos de M. Planas y José Gorina y Cia, estos dos últimos empleando al mismo viajante-, otro de un comerciante de Barcelona -Juan Fabra y Floreta - y otro de la casa madrileña Francisco Ruano e Hijos. En 1900 hemos encontrado seis, de los cuales dos pertenecen a algodoneras catalanas. Como se trata en los tres casos de muestras de cartas, las cifras absolutas no tienen particular valor. Por otra parte, en las cartas comerciales de Fortea no hay, para 1881, ninguna evidencia de viajantes visitando la casa comercial zaragozana, aunque la amplitud de la fuente, en este caso, es muy limitada. El único copiador para la segunda mitad del siglo XIX es el de diciembre de 1881. 
tes fijos, que en ocasiones también viajaban por su zona de influencia en busca de pedidos. Los agentes se establecían normalmente en grandes ciudades, como Madrid, Valencia, Sevilla, Málaga..., porque era necesario un mínimo de clientes potenciales para justificar la presencia permanente de alguien de la empresa. Todo parece indicar que agentes fijos y viajantes formaban parte de una misma lógica y que los unos no tenían mucho sentido sin los otros. Con sólo agentes fijos, una empresa hubiera podido acceder solamente a los núcleos de población más habitados, pero hubiera dejado grandes zonas del país sin cobertura, lo que le hubiera obligado a tener dos sistemas paralelos de comercialización. Además, en más de una ocasión se observa que uno de los viajantes realizaba una labor de coordinación sobre el territorio de todos los representantes de la empresa. Todo ello explica por qué agentes y viajantes aparecieron simultáneamente.

Por último, hay que subrayar que las nuevas formas de comercialización convivieron con las anteriores. Muchas de las ventas siguieron haciéndose en Barcelona a las grandes casas de comisión que, desde la capital catalana, canalizaban los géneros a través de sus sucursales, y a los mayoristas de provincias que siguieron desplazándose - ahora en ferrocarril- a Barcelona, y a Sabadell y Terrassa en el caso de la lana, a escoger y encargar géneros ${ }^{41}$.

En suma, podemos concluir que entre los setenta y los noventa del siglo XIX, los algodoneros catalanes construyeron sus estructuras comerciales en el mercado español. La intensidad y la cronología de este proceso no fue el mismo en todas las empresas, dependiendo probablemente de las diferencias del tamaño de la empresa y del tipo de producto, desempeñando las grandes firmas más pronto sus funciones comerciales que las pequeñas, así como aquéllas que fabricaban productos diferenciados y conectados con la moda tenían unas estructuras comerciales más desarrolladas que las que fabricaban tejidos estandarizados. En cualquier caso, más pronto o más tarde la mayoría de las empresas del sector, al menos aquellas que superaban un tamaño mínimo, acabaron adoptando el nuevo sistema de comercialización.

\section{Las funciones de los viajantes y los agentes fijos}

La descripción de las funciones que realizaban los viajantes y los agentes fijos de las empresas algodoneras nos va a ayudar a entender qué supuso el cambio de sistema. Sus actividades eran muy similares a las que ya se realizaban en los años cuarenta desde el almacén de Muntadas Hnos. en Madrid, o las que desarrolló el agente de La

41 Para las dos ciudades vallesanas, véanse Benaul (1991) y Deu (1993), (1996), (1997), (1999a) y (1999b). 
España Industrial en Zaragoza en la segunda mitad de los años cincuenta. La diferencia es que ahora el sistema permitía abarcar la totalidad del mercado español y que, a diferencia de los anteriores experimentos, se consolidó como un nuevo modo de comercializar los tejidos.

\subsection{Fomento de las ventas propias}

Uno de los motivos para integrar la comercialización, el más obvio, era conseguir pedidos. Para ello los viajantes recorrían las distintas poblaciones, normalmente un par de veces al año, para visitar a los comerciantes de provincias y ofrecerles, con los muestrarios, los productos de la empresa. Los agentes fijos hacían lo mismo en la ciudad donde estaban establecidos y, en muchas ocasiones, en las provincias bajo su radio de influencia. Aunque la política de precios y descuentos era fijada por la central, en ocasiones los representantes pedían hacer excepciones, o concesiones especiales, en función de la importancia del cliente o de la coyuntura de la plaza ${ }^{42}$.

Sin embargo, aunque el objetivo último de cualquier estructura comercial es siempre aumentar las ventas de la empresa, los vendedores no se limitaban a presentar las muestras y a tomar los pedidos. Las estructuras que montaron los fabricantes en este período eran, sobre todo, un instrumento para obtener información que, en último término, les debería permitir vender más y, algo no irrelevante, cobrar todo aquello que vendieran.

\subsection{Feed-back con la demanda e información sobre la competencia}

Un tipo de información que era muy útil para la empresa era la referida a los gustos de los consumidores, a los diseños que tenían más éxito en cada zona, tanto los propios como los de los competidores. Como ya hemos dicho, esto era particularmente importante para aquellas empresas que producían tejidos diferenciados, en el que el diseño era un componente importante del valor del producto. Por ejemplo, La España Industrial trataba de diferenciarse de las demás empresas por los dibujos de sus estampados, que cambiaba cada año. Obviamente, acertar o no con unos buenos

42 Por ejemplo, en 1895 el agente de La Rambla en Zaragoza había negociado una rebaja del precio con un cliente importante, y estaba a la espera de que la empresa confirmara el acuerdo: “...los Sres. Ros (...) hacen durante el año un bonito consumo, pagan bien, su marcha es á mayor negocio y sería una lástima contrariarlos y fuesen á consumir otra marca. Para obtener este pedido ya lo hemos tenido que trabajar bastante! Sentiríamos no accediesen Vs.". AHCVG, Carta de Eusebio Casajús a La Rambla, 7/01/1895. 
dibujos, que gustaran, o no, a los consumidores, podía condicionar mucho las ventas de la temporada. Por lo tanto, para la algodonera de Sants era esencial tener un canal directo de información de la respuesta de la demanda a los diseños nuevos de cada temporada, ya que su producción variaba según las señales que recibía del mercado. Necesitaba, en definitiva, tener feed-back con la demanda.

Por ejemplo, en 1870 el viajante José Sureda recomendaba desde Pamplona realizar algún otro diseño parecido a los que tenían éxito:

"En toda esta parte del norte se consumen bastantes indianas listadas para delantales, por el estilo de los números 725 y 740 de la lista núm. 18, así es que si Vs. consideran conveniente podrían servirse mandar hacer algun otro dibujo por el mismo órden y no dudo tendrian buena aceptacion" ${ }^{\prime \prime 3}$.

Y el mismo año, desde Zaragoza, se hacía eco de las quejas de los clientes respecto a la fabricación de un tipo de indianas:

"Muy poco venden estos corresponsales y tambien los de la parte de Valladolid y Burgos, las indianas vapor $1^{a} 68$. Debido á que las mugeres gastaban esta clase de indianas, dicen que pierde mucho el color; así es que creo, por si Vs. lo consideran conveniente, no mandar pintar mucho de estas indianas ${ }^{\prime \prime 4}$.

Es decir, la fabricación de la empresa variaba sobre la marcha, adaptándose a las señales que los consumidores le enviaban a través de su estructura comercial. Es obvio que cuanto más implicada estuviera la empresa en las ventas de sus productos, cuanto más abajo de la cadena de distribución llegara, antes percibiría las reacciones de los consumidores a sus tejidos y más rápido podría adaptar su fabricación a las exigencias de la demanda.

Sin embargo, también empresas con una gama de productos mucho más simple, como La Rambla, una vez establecida su estructura comercial, recibía de sus agentes y viajantes consejos sobre cómo variar su producción en función de la reacción de sus clientes. Así, en 1895 su agente en Zaragoza, Eusebio Casajús, afirmaba:

“Los Sres. Ros Hermanos estan descontentos con los Curados M por que sus clientes les devuelven cuanta confección mandan de esta clasé; dicen tendran que buscar otra clase para sustituir ésta" 45 .

43 ANC, Carta de José Sureda a La España Industrial, 16/03/1870, caja 27.60, n. 204.

44 ANC, Carta de José Sureda a La España Industrial, 23/03/1870, caja 27.60, n. 207.

45 AHCVG, Carta de Eusebio Casajús de Zaragoza a La Rambla, 28/12/1895. 
Informar sobre el éxito de los propios tejidos llevaba en muchas ocasiones a hablar de los productos de los competidores. Fabricando productos diferenciados, las empresas trataban de obtener cierto poder de mercado que les permitiera ganar un margen de beneficio por encima de la media.

No obstante, las empresas competían entre sí, y si una acertaba más con un diseño, perjudicaba las ventas de las otras, que trataban de reaccionar rápidamente copiando a la primera. Así, en 1870 el viajante de La España Industrial José Sureda denunciaba desde Madrid las estratagemas de otros fabricantes, consistentes en copiar los diseños de su empresa:

"Para que vean Vs. como hay fabricantes que copian los dibujos, acompaño dos muestras de indianas muebles, la una (...) es de José Palou, y la otra de Masriera. Tanto la una como la otra, aunque es género malo, lo vende el Sr. Avial, quien me ha entregado dichas muestras, á 2,80 metro" ${ }^{\prime \prime 6}$.

Sin embargo, la propia algodonera de Sants en 1879 recomendaba a Pascual Sánchez, un vendedor recién contratado para la zona de Valencia, que les enviara todas las muestras de tejidos de otros fabricantes que viera que tuvieran éxito:

“Puede V. remitirnos desde luego las muestras a que hace referencia y no solo estas sino todas cuantas crea V. que puedan convenir á nuestra fabricacion le apreciamos que nos las remita siempre sin consultarnos" ${ }^{\prime \prime 7}$.

El mismo agente contaba ocho años más tarde la reacción de un competidor al darse cuenta que La España Industrial le estaba quitando los clientes con un diseño muy parecido al suyo:

“El director de la fabril de Reus ha llegado hoy con un gran disgusto por la competencia que le hace V. con la nueva clase superior B y ha ofrecido bajar su precio á cuatro sesenta el metro de cuatro noventa y cinco que facturaba, pero opino yo y conmigo otros, que si no hace otra cosa no adelantará nada con esto: también ha dicho que si V. hace esta clase y no le deja vender, que el haría todas las demás que V. fabrica y que entrará en competencia con todas..." 48 .

\footnotetext{
46 ANC, Carta de José Sureda a La España Industrial, 22/01/1870, caja 27.60, n. 178.

47 ANC, Carta de La España Industrial a Pascual Sánchez, 27/11/1879, copiador 26.2.47, p. 43.

48 ANC, Carta de Pascual Sánchez a La España Industrial, 1/02/1887, caja 27.117, n. 20.
} 
Queda claro que las distintas empresas intentaban "pisarse" los diseños unas a otras y que, en ello, las estructuras propias de información jugaban un papel importante. En la correspondencia de viajantes y agentes fijos con sus empresas, aparecen constantemente referencias a los tejidos de otros fabricantes, incluidos los extranjeros, que quitaban ventas a sus propios productos. Por ejemplo, en 1895, el agente de La Rambla en Zaragoza, Eusebio Casajús, enviaba dos piezas de telas de un competidor y explicaba cómo lo había hecho para averiguar el precio:

“...les remito dos muestras Curados de la Solidez (...) Ambos tipos los he tomado a Ciria, que respecto á precios nada he podido sacarle, pero en vista de esto he pasado á casa Ros Hnos. y disimuladamente le he preguntado á Valero el precio que la Solidez le habia ofrecido los Curados..." 49 .

Y en 1900, el viajante José Vidal informaba desde Palencia a La España Industrial:

“Desde Valladolid remití á V. unas muestras de percalinas cruzada que vende Riva y Garcia al precio de 2,25 rs. y otra de raso que fabrica J. Barrera al precio de 3,40 rs. con el 6 p\% dto. las mandé para que V. vieran lo que hacen los demás fabricantes (...) Ferrer y Vidal factura este articulo a 1,55 rs. con dibujos fondo blanco y fondo n/ (...); y Casas y Jover á 1,50 rs. los dos con 6 p\% dto. así y todo como grandes partidas no venden pero estos artículos labrados á los citados precios imposibilitan algo la venta de los armures" 50 .

\subsection{Análisis de la solvencia de los clientes}

Tan importante como la información acerca del éxito de los propios productos y de los de la competencia, lo era aquélla acerca de la solvencia de los clientes, sobre todo de los nuevos. La correspondencia entre las empresas textiles y sus agentes y viajantes está llena de referencias a la capacidad económica de posibles nuevos clientes, a su cifra de negocios, a su solidez financiera. Así, Eusebio Casajús, representante de La Rambla en Zaragoza, escribía en 1895:

"Sera facil visite a Vs. éstos dias un muchacho establecido de poco en ropas hechas Dn. José M. Alonso; pueden decirle precios para tiendas; nos han dado buenas referencias"

AHCVG, Carta de Eusebio Casajús a La Rambla, 4/12/1895.

ANC, Carta de José Vidal a La España Industrial, 16/04/1900, caja 27.155, n. 25.

AHCVG, Carta de Eusebio Casajús a La Rambla, 26/01/1895. 
Tener a alguien sobre el terreno, que pudiera preguntar a los miembros de la comunidad local, permitía obtener una información que era muy difícil de adquirir desde Barcelona. Por ejemplo, en 1870 el viajante de La España Industrial en la zona de Andalucía, Andrés G. y Gallardo, contactó con un corredor de letras para recabar referencias sobre un posible cliente en Jaén:

“...hoy me he informado del estado de la casa de los Sres Torres y Trajas y por ahora no ofrece cuidado de ninguna especie, asi al menos me lo aseguran todos y en especial estos Sres. D. Matias Saenz y Cia los cuales por su negocio de letras suelen estar al corriente del estado de las demas casas" 12 .

Asimismo, en el mismo año, el viajante José Sureda informaba de los apoyos financieros con los que contaba un mayorista de Bilbao:

“...he sabido por mediación de este Sr. Saurí y de un corredor llamado Morales de esta, y amigo, que la casa de dicho Sr. Suñol seguía bien, pues á mas de tener un crédito abierto en este Banco de 6000 duros, le protege su ex socio Sr. Magivel" ${ }^{\prime 23}$.

En ocasiones, la empresa tomaba el que otros fabricantes catalanes vendieran directamente a determinado comerciante como una prueba de que se podía confiar en él ${ }^{54}$.

Esta preocupación por la solvencia financiera se explica porque el comercio textil se realizaba mayoritariamente a crédito. Los fabricantes abrían cuenta a sus clientes, que iban pagando sus compras a un plazo determinado, que oscilaba entre uno y cuatro meses. Por consiguiente, vender comportaba un riesgo, el de no cobrar las ventas que se habían realizado. Para conjurar este riesgo, los fabricantes procuraban conocer a sus clientes y establecer con ellos una relación de largo plazo.

La puesta en pie de una estructura comercial propia en el mercado español supuso una oportunidad para los fabricantes de llegar directamente a toda una serie de comerciantes a los que hasta entonces no conocían. Uno de los incentivos para involucrarse en la venta de los propios tejidos era "puentear" las casas de comisión de Barcelona, que hacían de intermediarios entre las empresas textiles y los mayo-

52 ANC, Carta de Andrés G. y Gallardo a La España Industrial, 4/05/1870, caja 27.58, n. 147.

53 ANC, Carta de José Sureda a La España Industrial, 6/03/1870, caja 27.60, n. 199. El mismo viajante desestimaba un nombre propuesto por la empresa en Alicante, debido a que no tenía establecimiento propio. Carta de José Sureda a La España Industrial, 30/05/1870, caja 27.60, n. 223.

54 Antonio Ruiz, agente en Mallorca, escribía: “...por ahora solo se dice de dicho Sr. [Pablo Segura] que es moroso en los pagos; sin embargo veo recibe mucho genero de esa". ANC, Carta de Antonio Ruiz a La España Industrial, 6/04/1880, caja 27.94, n. 82. 
ristas de provincias ${ }^{55}$. Precisamente dichas casas basaban su negocio en el conocimiento que tenían de las comunidades mercantiles de las distintas ciudades. Para intentar sustituirlas, los fabricantes debían disponer de sus propias estructuras de información, que les permitieran vender a esos nuevos clientes con un mínimo de garantías ${ }^{56}$.

Este esfuerzo por estar bien informados acerca de los potenciales clientes generó algunas iniciativas colectivas, como la que llevó a cabo el Gremio de Fabricantes de Sabadell: La Unión Lanera Española. Esta institución elaboraba informes sobre la solvencia de los clientes de sus asociados con la ayuda de los viajantes y agentes, y además actuaba de forma solidaria cuando se producían impagos ${ }^{57}$. Otras sociedades, como Fulgencio Isaura y Cía. ${ }^{58}$, la Seguridad Comercial ${ }^{59}$ o La Salvadora ${ }^{60}$ se dedicaban a gestionar los créditos morosos de sus socios, fabricantes o comerciantes textiles, y a indemnizarlos en caso de impagos definitivos.

\section{La consolidación del papel de los viajantes y agentes en el primer tercio del siglo XX}

Toda la evidencia proveniente de los archivos de algodoneras y de empresas comerciales conduce a pensar que el sistema de viajantes y agentes fijos estaba plenamente consolidado en el primer tercio del siglo XX. Esta imagen coincide con la transmitida por la gente que vivió después de la Guerra Civil: el viajante era la piedra angular de la comercialización de los tejidos de algodón catalanes.

Recordemos que en el apartado anterior hemos dicho que Viladomiu tenía en 1905 cuatro agentes fijos y cuatro viajantes. En 1913 contaba con cinco agentes fijos y dos viajantes. Entre los primeros continuaban los mismos en Valencia, Murcia y

55 En la correspondencia se refleja la intención de La España Industrial, en el momento en que está estableciendo su estructura comercial propia, de llegar directamente a muchos mayoristas y minoristas de provincias. ANC, Carta de José Sureda a La España Industrial, 10/05/1870, caja 27.60, n. 229.

56 Vender a través de una casa de comisión era la mejor opción cuando no se estaba muy seguro de la solvencia del cliente. ANC, Carta de Pascual Sánchez a La España Industrial, 16/06/1880, caja 27.94, n. 58.

57 Deu (1993) y (1995).

58 La primera escritura en la que aparece la sociedad Fulgencio Isaura y Cía. es de 1856. AHMB, Notario de Barcelona Fernando Moragas Ubach, 10/01/1856, BDEE n. 8356100551.

59 AHCA, Expediente de La sociedad Seguridad Comercial vs Jaime Pala y Coll, Origen autos: pago cantidades (exp. 3164, año 1860); Expediente de La Seguridad Comercial vs Ramon Arabia, Origen autos: pago cantidades (exp. 1167, año 1861); Expediente de la Seguridad Comercial vs D. José Solanas y Angala, Origen autos: pago cantidades (exp. 1168, año 1861); Expediente de quiebra de la casa de Garcia y Páramo (exp. 10068, año 1861).

60 AHCA, Expediente de la sociedad anónima La Salvadora vs Pelegrin Tintoré, Origen autos: pago de cantidades (exp. 3162, año 1860). 
CUADRO 2

NÚMERO DE VIAJANTES Y AGENTES FIJOS

\begin{tabular}{lccccc}
\hline & 1913 & 1920 & 1926 & 1930 & $1944-1948$ \\
\hline $\begin{array}{l}\text { La España Industrial } \\
\text { La Rambla }\end{array}$ & 9 & & \multicolumn{2}{c}{9} \\
$\begin{array}{l}\text { Viladomiu } \\
\text { Manufacturas Valls }\end{array}$ & 7 & 7 & 10 & 12 & 17 \\
\hline $\begin{array}{l}\text { Fuentes: ANC, Libros mayores y cartas de La España Industrial, Viladomiu y Manu- } \\
\text { facturas Valls para varios años; y AHCVG, Libros mayores y cartas de La } \\
\quad \text { Rambla para varios años. }\end{array}$ &
\end{tabular}

Málaga, había desaparecido el de Granada y se habían añadido uno en Palma de Mallorca y otro en Sevilla. En 1920-1921 tenía también siete personas trabajando en una estructura comercial que cubría todo el mercado español. Uno de ellos, Antonio Seguer, era un viajante que cubría la mitad de España - Castilla, Galicia, costa cantábrica y valle del $\mathrm{Ebro}^{61}$ — , otros cinco eran agentes fijos —en Palma de Mallorca, Valencia, Murcia, Málaga y Sevilla- que cubrían la otra mitad ${ }^{62}$, y el séptimo, Francisco Casademont, era un viajante que cubría la misma área que los agentes fijos, con la excepción de Mallorca ${ }^{63}$, reforzando su trabajo ${ }^{64}$. En 1926, Viladomiu estableció tres nuevos agentes, en Granada, La Coruña y Santa Cruz de Tenerife ${ }^{65}$ (Cuadro 2).

Por su parte, La España Industrial en 1913 había aumentado el número de vendedores respecto a 1900, pasando de cinco a nueve. Ahora contaba con cinco agentes fijos - Madrid, Tenerife, Zaragoza y dos en Valencia ${ }^{66}$-, dos viajantes ${ }^{67}$, un agente

61 Antonio Seguer trabajaba para Viladomiu desde 1902.

62 Vda. de Luis Fábregas en Palma, Francisco Sancho en Valencia, Juan Abizanda en Murcia, Francisco Lozano en Málaga y Vda. de José Jiménez en Sevilla.

63 Aparece en las cartas a Francisco Sancho (Valencia), Juan Abizanda (Murcia), Vda. de José Jiménez (Sevilla), y sabemos que en 1920 visitó también Málaga. ANC, copiador 12.01.01.

64 “... seguramente a fines de la presente semana se hallará en esa nuestro viajante Sr. Casademont, quien le indicará algunas orientaciones referente a determinados artículos y precios...". ANC, Carta de Viladomiu a Francisco Sancho en Valencia, 1/6/1921, copiador 21.01.02, p. 112.

65 Arcadio Sánchez Gazques en Granada, Antonio Ramírez en La Coruña y Ramoneda Ferrer en Tenerife. Por otra parte, Francisco Beut había sustituido a Francisco Sánchez en Valencia. ANC, libro mayor II07.03.02.03, pp. 147-151.

66 Uno de los establecidos en la capital del Turia se dedicaba sólo al sector de las telas para encuadernación.

67 Esteban Rabada realizó cuatro viajes ese año, pasando por Málaga, Sevilla, Madrid, Talavera, Orense, Vigo, Santiago, León, Oviedo, Santander, Burgos, Valladolid, Badajoz, Granada y Valencia. Por su parte, Narciso Rucabado hizo sólo un viaje, pasando por Santander, Salamanca, Badajoz, Albacete, Valencia y Logroño. 
en Bilbao que también viajaba ${ }^{68}$ y un representante en Montevideo ${ }^{69}$. En 1930 seguía con nueve vendedores. Cuatro de ellos eran agentes en Sevilla, Bilbao, Valencia y Zaragoza. Tres eran viajantes: Ramón Casafont cubría Cataluña y Mallorca; Sebastián Solá, Aragón y Levante; y Narciso Rucabado, Galicia, gran parte de Castilla, Extremadura y Andalucía. Además, un cliente situado en Lisboa actuaba también de agente en esa ciudad, mientras que Luis Calvet realizó un viaje por cuenta de la empresa "para facilitar la venta de géneros" en Argentina, Uruguay y Chile.

Ese mismo año 1930, La Rambla contaba con doce personas trabajando por todo el territorio español. Dos de ellos eran agentes fijos —en Madrid y Valencia-, cinco viajantes, y otros cinco eran viajantes que, establecidos en una ciudad, cubrían una determinada zona ${ }^{70}$.

La correspondencia que el mayorista zaragozano Fortea mantenía con sus proveedores esos mismos años confirma que los viajantes eran empleados de forma general por las empresas textiles, tanto algodoneras como laneras. Así, hacían referencia a "su viajante el Sr. Vázquez" en una carta enviada a Sedón1, al igual que con la lanera Viuda de José Marcet Poal de Terrassa ${ }^{72}$ o la de género de punto Cooperación Fabril S.A. de Olot ${ }^{73}$.

Por último, en el período 1944-1948 Manufacturas Valls tuvo, de promedio, diecisiete personas trabajando en su estructura comercial, la mayoría de ellas establecidas en varias ciudades, y cinco de ellas que eran viajantes. Así pues, justo después de la Guerra Civil, el sistema de comercialización de la industria algodonera catalana era el mismo que el establecido en el último tercio del siglo XIX.

En definitiva, queda claro que el sistema de viajantes y agentes fijos que se había implantado en el último tercio del siglo XIX se consolidó plenamente en el primer tercio del XX y llegó hasta después de la Guerra Civil. Las empresas ampliaron y perfeccionaron sus estructuras de comercialización directa, disponiendo de más gente sobre el terreno y llegando cada vez a más rincones del país.

¿Qué efectos tuvo a largo plazo la instauración de este nuevo sistema en las ventas de las empresas algodoneras? Aunque uno de los motivos por los que éstas se decidieron a emplear viajantes y agentes fijos fue el fomento de sus ventas frente a las de la competencia, al generalizarse el sistema los posibles aumentos de cuota de

\footnotetext{
68 José Ribera Font, que realizó un viaje en invierno de ese año por San Sebastián, Logroño y Burgos.

69 José Botet intervino en varias operaciones como comisionista desde la ciudad del Río de la Plata.

70 AHCVG, Cartas enviadas y recibidas por La Rambla en 1930.

71 Archivo Fortea (AF, en adelante), Carta enviada el 28/4/1927, copiador L-181, p. 437. También hacen referencia a un viajante de Viladomiu en 1930. AF, Carta enviada el 19/5/1930, copiador L-197, p. 97.

72 “...estos gabanes que nos permitirnos devolverle de su factura 24 de Septbre. Ppdo. Por estar barrado, de conformidad con su viajante". AF, Carta enviada el 14/5/1930, copiador L-197, p. 43.

73 AF, Carta enviada el 22/7/1930, copiador L-198, p. 85.
} 
mercado se anulaban unos a otros. Así, si observamos la evolución de las ventas de las empresas analizadas, no hay una tendencia clara. Al fin y al cabo, el consumo total de tejidos de algodón por parte de los españoles dependía de la evolución de su renta y de los precios relativos y, como ya ha señalado la historiografía, los años en los que se generalizaron los viajantes no fueron los más expansivos del sector ${ }^{74}$.

Lo que sí se podía esperar era un cambio en la distribución geográfica de las ventas y en el tipo de cliente de las algodoneras. Al disponer de estructuras de comercialización propias, es lógico que ahora las fábricas llegaran directamente a más localidades que antes y contactaran con comerciantes más pequeños. Un análisis a largo plazo de las estructuras de ventas de La España Industrial y La Rambla confirman esta hipótesis: entre 1860 y 1930 se observa una sustitución del peso de Barcelona y de sus grandes casas comerciales por las ciudades de más de 50.000 habitantes y, en menor medida, por las de la franja entre 20.000 y 50.000. Sin embargo, los cambios fueron limitados y el sistema de distribución de tejidos de algodón siguió siendo jerarquizado. Las grandes casas de comisión de Barcelona continuaron controlando una parte importante de las ventas de las algodoneras —en 1930 aún un 43 por 100 de la facturación de La España Industrial se hacían en la ciudad condal- y su pérdida de peso fue principalmente en beneficio de los mayoristas de provincias y, sólo de forma muy limitada, de los establecimientos minoristas.

\section{Conclusiones}

Los fabricantes algodoneros catalanes se implicaron más que los británicos en la comercialización de sus productos. Sin embargo, su comportamiento no fue excepcional si se sitúa en el contexto internacional. En España, como en los principales países industriales europeos, no existía una especialización tan clara entre la esfera productiva y la comercial. Es la especificidad del distrito algodonero del Lancashire, su particular forma de organizar la producción desde las casas comerciales, sin implicarse directamente en la fabricación, el hecho que explica la excepcionalidad británica. En cambio, la integración vertical de producción y comercialización no se produjo en España, ni en los otros países continentales, de forma completa. Siempre se canalizó una parte importante de los géneros a través de comerciantes independientes, incluso después de los cambios que se iniciaron en la década de 1860. 
En el último tercio del siglo XIX las fábricas algodoneras catalanas integraron la comercialización a través del establecimiento de unas estructuras de viajantes y agentes fijos que abarcaban todo el mercado español. Había diversos incentivos para integrar la comercialización: el simple deseo de promover la venta de los propios productos, la necesidad de feed-back con la demanda, el deseo de evitar las comisiones de los intermediarios, la necesidad de conocer la solvencia de los clientes... Estos incentivos ya existían en el momento de la mecanización del sector (años cuarenta y cincuenta) y estaban detrás de las distintas iniciativas de integración vertical de producción y comercialización. Sin embargo, lo que propició el cambio de sistema fue un cambio tecnológico, la aparición del ferrocarril, que permitió que una empresa fabril grande o media pudiera llegar directamente a todo el mercado español con unos pocos vendedores. La mayor o menor presencia de los factores anteriormente mencionados podían determinar la velocidad en la adopción de la nueva estructura comercial. El caso de la diferenciación de producto es un buen ejemplo: aquellas empresas con un producto mucho más ligado a la moda tenían mayor necesidad de feed-back con el consumidor y, por tanto, mayor incentivo para establecer su propia red.

\section{Fuentes}

Arxiu Nacional de Catalunya (ANC)

La España Industrial, Sedó, Viladomiu, Burés y Manufacturas Valls.

Arxiu Històric Comarcal de Vilanova i la Geltrú (AHCVG)

La Fábrica de la Rambla.

Arxiu del Museu del Tèxtil i l'Estampació de Premià de Mar (AMTEPM)

Muntadas Hermanos.

Arxiu Històric Municipal de Barcelona (AHMB)

Fondo Comercial de Batllori y Cia.

Archivo Fortea (AF, Facultad de CC. Económicas de la Universidad de Zaragoza)

Casa Fortea.

Archivo Masaveu (AM, Oviedo)

Fondo Masaveu.

Arxiu Històric de la Corona d'Aragó (AHCA)

Expedientes del Tribunal de Comercio de Barcelona. 


\section{Bibliografía}

BENAUL, Josep M. (1991): La indústria tèxtil llanera a Catalunya, 1750-1870. El procés d'industrialització al districte industrial de Sabadell-Terrassa, Tesis Doctoral, Universidad Autónoma de Barcelona.

-(1992): "Los orígenes de la empresa textil lanera en Sabadell y Terrassa en el siglo XVIII", Revista de Historia Industrial, 1, pp. 39-62.

-(1993): "La comercialització dels teixits de llana en la cruïlla dels segles XVIII i XIX.

L'exemple de la fàbrica de Terrassa 'Anton i Joaquim Sagrera', 1792-1807", Arraona, 13 , pp. 35-47.

BESSO, Sabbato L. (1910): The Cotton Industry in Switzerland, Vorarlberg and Italy, Manchester, Manchester University Press.

BOVA, Francesca (1993): Multinazionalizzazione e immigrazione: i differenti modelli di insediamento dell'imprenditoria estera nell'industria cotoniera italiana (1860-1910), Tesis Doctoral, Florencia, Instituto Universitario Europeo.

BROADBERRY, Stephen, y MARRISON, Andrew (2002): “External Economies of Scale in the Lancashire Cotton Industry, 1900-1950", Economic History Review, 55 (1), pp. 51-77.

BROWN, John C. (1992): "Market Organization, Protection, and Vertical Integration: German Cotton Textiles before 1914", Journal of Economic History, 52 (2), pp. 339351.

-(1995): "Imperfect Competition and Anglo-German Trade Rivalry: Markets for Cotton Textiles before 1914", Journal of Economic History, 55 (3), pp. 494-527.

CASTRONOVO, Valerio (1965): L'industria cotoniera in Piemonte nel secolo XIX, Torino, Archivio Economico dell'Unificazione Italiana, serie II, vol. XI.

CLARK, W. A. Graham (1908a): Cotton textile trade in Turkish Empire, Greece and Italy, Washington, Department of Commerce and Labor, Bureau of Manufactures, Government Printing Office.

-(1908b): Cotton fabrics in Middle Europe: Germany, Austria-Hungary, Switzerland, Washington, Department of Commerce and Labor. Bureau of Manufactures, Government Printing Office.

CHAPMAN, Stanley D. (1992): Merchant enterprise in Britain: from the Industrial Revolution to the World War I, Cambridge, Cambridge University Press.

CHASSAGNE, Serge (1991): Le cotton et ses patrons. France 1760-1840, Paris, Éditions de l'École des Hautes Études en Sciences Sociales.

DEHN, Richard M. R. (1913): The German Cotton Industry. A report to the electors of the Gartside Scholarships, Manchester, Manchester University Press.

DEU, Esteve (1993): “La comercialización de tejidos de lana catalanes: Informes de la Unión Lanera Española, 1881-1924", Actas del V Congreso de la AHE, San Sebastián, pp. 14-21. 
-(1995): “La comercialització dels teixits de llana catalans. Informes de La Unión Lanera Española, 1881-1924", Arraona, 16, pp. 61-71.

-(1996): “El comercio de tejidos de lana catalanes en España, 1870-1914”, en PÉREZ

PICAZO, M. Teresa; SEGURA, Antoni, y FERRER, Llorenç (eds.), Els catalans a Espanya, 1760-1914, Catarroja, Afers, pp. 357-363.

-(1997): "El comercio de tejidos de lana catalanes en Andalucía, 1870-1914", Segun-

do Congreso de Historia Catalano-Andaluza, Cataluña y Andalucía en el siglo XIX.

Relaciones económicas e intercambios culturales, Barcelona, Aquí and Multimedia S.

L., pp. 141-157.

-(1999a): “Distribución de tejidos de lana en el mercado español, 1870-1935”, en CARRERAS, Albert; PASCUAL, Pere; REHER, David, y SUDRIÀ, Carles (eds.), Doctor Jordi Nadal. La industrialització i el desenvolupament econòmic d'Espanya, Barcelona, Edicions de la Universidad de Barcelona, Vol. II, pp. 1175-1187.

-(1999b): "La comercialización de tejidos catalanes en Castilla-León y Cantabria, 1870-1914", en TORRAS, Jaume, y YUN, Bartolomé (dirs.), Consumo, condiciones de vida y comercialización: Cataluña y Castilla, siglos XVII-XIX, Ávila, Junta de Castilla y León, Consejería de Educación y Cultura, pp. 377-393.

EDWARDS, Michael M. (1967): The Growth of the British Cotton Trade, 1780-1815, Manchester, Manchester University Press.

EINAUDI, Luigi (1900): Un principe mercante. Studio sulle espansione coloniale italiana, Torino, Fratelli Bocca Editori.

FARNIE, Douglas (1979): The English Cotton Industry and the World market, 1815-1896, Oxford, Clarendon Press.

-(2004): "The role of merchants as prime movers in the expansion of the cotton industry, 1760-1990" en FARNIE, Douglas, y JEREMY, David (eds.), The Fibre that changed the World. The Cotton Industry in International Perspective, 1600-1990s, Oxford y New York, Oxford University Press, pp. 15-55.

FOHLEN, Claude (1956): L'industrie textile au temps du Second Empire, Paris, Libraire Plon.

FONTANA, Josep (1971): La quiebra de la monarquía absoluta, Barcelona, Ariel.

FORRESTER, Robert B. (1921): The Cotton Industry in France. A report to the electors of the Gartside Scholarships, Manchester, Manchester Universisty Press.

FRADERA, Josep M. (1987): Indústria i Mercat. Les bases comercials de la indústria catalana moderna, Barcelona, Crítica.

FRENCH, Michael (2005): “Commercials, careers, and culture: travelling salesmen in Britain, 1890s-1930s", Economic History Review, 58 (2), pp. 352-377.

GALÍ, Roser (2002): "Crédito comercial e inversión fabril. El 'holding' Nadal y Ribó", Revista de Historia Industrial, 22, pp. 45-77.

GARCÍA LÓPEZ, José R. (1987): Los comerciantes banqueros en el sistema bancario español, Gijón, Universidad de Oviedo. 
GODLEY, Andrew (2001): Jewish immigrant entrepreneurship in New York and London, 1880-1914: enterprise and culture, New York, Palgrave.

GÓMEZ ZORRAQUINO, J. Ignacio (1990): “Los primeros años de vida de la 'Casa Fortea' (1785-1850)", Teruel, 80-81, pp. 109-162.

MUSET, Assumpta (1993): Catalunya i el comerç peninsular al segle XVIII, Tesis Doctoral, Universidad de Barcelona.

-(1997): Catalunya i el mercat espanyol al segle XVIII: Els traginers i negociants de Calaf $i$ Copons, Barcelona, Publicacions de l'Abadia de Montserrat.

NADAL, Jordi (1975): El fracaso de la Revolución Industrial en España, 1814-1913, Barcelona, Ariel.

NADAL, Jordi, y MALUQUER, Jordi (1985): Catalunya, la fábrica d'Espanya, Barcelona, Ajuntament de Barcelona.

ODELL, Ralph M. (1912): Cotton goods in Italy, Special Agents Series, 48, Washington, Government Printing Office.

OLIVA, Benet (1999): Els orígens de la primera industrialització del rerapaís. Un cas emblemàtic: Vilassar i el capital comercial barceloní (1828-1875), Mataró, Premi Iluro 1998, Caixa d'Estalvis Laietana.

PÉREZ PICAZO, María Teresa; SEGURA, Antoni, y FERRER, Llorenc (eds) (1996): Els catalans a Espanya, 1760-1914, Catarroja, Afers.

PRAT, Marc (2004): “Fabricar i comerciar a mitjan segle XIX: els casos dels Muntadas i els Batllori", Recerques, n. 47-48, pp. 29-49.

-(2005): "La utilización de redes empresariales para la comercialización de tejidos catalanes a mediados del siglo XIX", comunicación en el X Simposio de Historia Económica, UB-UAB-UPF, Bellaterra (Barcelona), 27-29 Enero.

-(2006): Fabricantes, comerciantes y banqueros. Las estructuras comerciales de la industria algodonera catalana en el mercado español (1840-1936), Tesis Doctoral, Instituto Universitario Europeo, Florencia.

-(2007): "Vertical integration or specialisation: producing and commercialising cotton goods (1815-1913)", Documents de Treball de la Facultat de Ciències Econòmiques i Empresarials de la UB, E07/188, Barcelona, Universitat de Barcelona.

PRATT, Edward Ewing (1917): Cotton Textiles. International trade and merchandising methods, Washington, Department of Commerce, Bureau of Foreign and Domestic Commerce, 58, Government Printing Office.

ROMANO, Roberto (1980): I Caprotti. L'avventura economica e umana di una dinastia industriale della Brianza, Milán, Francesco Angeli/Storia.

-(1992a): L'industria cotoniera lombarda dall'unità al 1914, Milán, Banca Commerciale Italiana.

-(1992b): “Le origini dell'espansione commerciale all'estero dell'industria cotoniera italiana", Atti del Seminario L'industria italiana nel mercato mondiale dalla fine dell'800 alla metà del'900, Torino, Archivio Storico Fiat, pp. 37-51. 
ROSE, Mary B. (2000): Firms, networks and business values: the British and American cotton industries since 1750, Cambridge, Cambridge University Press.

ROSÉS, Joan Ramon (1997): “La integración vertical en el sector algodonero catalán, 1832-1861", en LÓPEZ, Santiago, y VALDALISO, Jesús M. (eds.), ¿Que inventen ellos? Tecnología, empresa y cambio económico en la España contemporánea, Madrid, Alianza Editorial, pp. 249-280.

-(1998): The Early Phase of Catalan Industrialisation, 1830-1861, Tesis Doctoral, Instituto Universitario Europeo, Florencia.

SÁNCHEZ, Àlex (1989a): “La era de la manufactura algodonera en Barcelona, 17361839", Estudios de Historia Social, 48-49, pp. 65-114.

-(1989b): "L'estructura comercial d'una fàbrica d'indianes barcelonina: Joan Rull i Cia. (1790-1821)", Recerques, 22, pp. 10-24.

SOCIETAT D'ESTUDIS ECONÒMICS (1908): Informació sobre la necessitat de crear Banca Catalana, Barcelona, Societat d'Estudis Econòmics.

SOLÀ, Angels, y OLIVA, Benet (1997): “Tejidos catalanes en el mercado andaluz en la segunda mitad del siglo XIX. La organización de las ventas en sociedad en comandita", Segundo Congreso de Historia Catalano-Andaluza, Cataluña y Andalucía en el siglo XIX. Relaciones económicas e intercambios culturales, Barcelona, Aquí and Multimedia S. L., pp. 159-178.

SOLER, Raimon (2000): Estratègies empresarials en la indústria cotonera catalana. El cas de la Fàbrica de la Rambla de Vilanova, 1833-1965, Tesis Doctoral, Universidad de Barcelona.

TALLADA, Josep M. (1944): Barcelona económica y financiera en el siglo XIX, Barcelona Librería Dalmau.

TORRAS, Jaume (1987): “Fabricants sense fàbrica. Estudi d'una empresa llanera d'Igualada (1726-1765)", Recerques, 19, vol. I, pp.145-160.

-(1995):"Redes comerciales y auge textil en la España del siglo XVIII", en BERG, Maxine (ed), Mercados y manufacturas en Europa, Barcelona, Crítica, pp. 111-132.

VALLS, Francesc (2004): La Catalunya Atlàntica, Vic, Eumo.

VICENS, Jaume, y LLORENS, Montserrat (1958): Industrials i Politics, Barcelona, Vicens Vives.

VILAR, Pierre (1965): Catalunya dins l'Espanya moderna. La formació del capital comercial, vol.4, Barcelona, Edicions 62.

WHITTAM, William Jr. (1907): Report on England's Cotton Industry, Washington, Department of Commerce and Labor, Bureau of Manufactures, Government Printing Office. 